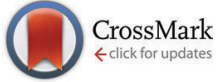

Cite this: Phys. Chem. Chem. Phys., 2016, 18, 26595

Received 29th July 2016, Accepted 7th September 2016 DOI: $10.1039 / c 6 c p 05276 b$

www.rsc.org/pccp

\title{
Mechanistic insights into lithium ion battery electrolyte degradation - a quantitative NMR study $\dagger$
}

\begin{abstract}
S. Wiemers-Meyer, ${ }^{a}$ M. Winter ${ }^{\mathrm{ab}}$ and S. Nowak ${ }^{{ }^{a}}$
The changes in electrolyte composition on the molecular level and the reaction mechanisms of electrolyte degradation upon thermal aging are monitored by quantitative NMR spectroscopy, revealing similar rates of degradation for pristine and already aged electrolytes. The data analysis is not in favor of an autocatalytic reaction mechanism based on $\mathrm{OPF}_{3}$ but rather indicates that the degradation of $\mathrm{LiPF}_{6}$ in carbonate based solvents proceeds via a complex sequence of "linear" reactions rather than a cyclic reaction pattern which is determined by the amount of water present in the samples. All investigated electrolytes are reasonably stable at temperatures of up to $60{ }^{\circ} \mathrm{C}$ in the presence of minor amounts or absence of water hence indicating that chemical instability of electrolyte components against water is decisive for degradation and an increase in temperature ("thermal aging") just accelerates the degradation impact of water.
\end{abstract}

\section{Introduction}

Currently, much effort is devoted to investigate the relation between chemical and physical properties and electrochemical performance of lithium ion battery materials. ${ }^{1-6}$ Early studies considering the electrolyte and its aging processes revealed that water and other protic impurities have a detrimental effect on the electrolyte stability at higher temperatures, ${ }^{7,8}$ while later the identification of degradation products (mainly from carbonate and $\mathrm{PF}_{6}{ }^{-}$) and kinetic studies came into focus thereby providing tentative reaction mechanisms ${ }^{9-14}$ in addition to a detailed report on degradation mechanisms of carbonate electrolyte solvents. ${ }^{15}$ Also, the applicability of various analytical methods to reliably monitor electrolyte aging processes including gas chromatography (GC), ${ }^{16-23}$ ion chromatography (IC), ${ }^{19,22,24-27}$ high pressure liquid chromatography (HPLC), ${ }^{17}$ electrospray ionization mass spectrometry (ESI-MS), ${ }^{17,22,24-27}$ infrared (IR) spectroscopy, ${ }^{28}$ inductively coupled or low temperature plasma mass spectrometry (ICP-MS), ${ }^{22,26}$ (LTP-MS) ${ }^{29}$ as well as optical emission spectroscopy (ICP-OES) ${ }^{22,25}$ or hyphenations of these methods was thoroughly reviewed.

Though most of these studies discuss qualitative data, the extent of $\mathrm{HF}$ release was estimated by titration with $\mathrm{NaOH}^{8}$ while $\mathrm{OPF}_{2} \mathrm{OEt}$ formation during electrolyte aging could be established

\footnotetext{
${ }^{a}$ University of Muenster, MEET Battery Research Center, Institute of Physical

Chemistry, Corrensstraße 46, 48149 Muenster, Germany.

E-mail: sascha.nowak@uni-muenster.de

${ }^{b}$ Helmholtz Institute Münster, IEK-12 of Forschungszentrum Jülich,

Corrensstrasse 46, Münster, Germany

$\dagger$ Electronic supplementary information (ESI) available. See DOI: 10.1039/ c6cp05276b
}

by nuclear magnetic resonance (NMR) spectroscopy. ${ }^{11,14}$ Other reports include a quantification of carbonates and their degradation products based on HPLC and GC methods, ${ }^{17,19}$ that in principle allow for a separation of non-ionic electrolyte components. Nevertheless, to the best of our knowledge, there is no detailed report available that quantitatively considers the degradation products of the rather abundantly applied electrolyte $1 \mathrm{M}$ $\mathrm{LiPF}_{6}$ in a mixture of ethylene carbonate (EC) and dimethyl carbonate (DMC) though unraveling of molecular electrolyte aging mechanisms could afford unprecedented ways to either prevent or at least defer occurring aging phenomena. Therefore, in this work, the impact of various experimental conditions on both the electrolyte stability and aging processes are systematically elucidated. In addition, monitoring the occurrence of potentially toxic compounds may yield crucial data for further industrial safety evaluations. Since the compounds likely involved in electrolyte aging contain NMR-active nuclei such as e.g., fluorine, phosphorous or hydrogen multinuclear solution NMR spectroscopy is applied for identification and quantification of molecular species present in the considered aged electrolytes where the use of gas-tight flame-sealed NMR tubes with polytetrafluoroethylene (PTFE) tube liners should allow for equilibrium conditions at least at the timescale of the experiments.

\section{Experimental}

\subsection{Materials}

Battery grade SelectiLyte ${ }^{\mathrm{TM}}$ LP30 was purchased from BASF (Germany). It consists of $\mathrm{LiPF}_{6}\left(1 \mathrm{~mol} \mathrm{~L}^{-1}\right)$ in EC:DMC (1:1 by weight). The water content of the electrolyte was 
measured with an 851 Titrando Karl Fischer Coulometer (Metrohm, Switzerland). The content was determined to be 68 ppm. Deionized water was obtained from a Milli-Q water system (Merck Millipore, USA). Acetonitrile (LC grade) was ordered from VWR (Germany), all other chemicals were purchased from Sigma-Aldrich (USA) and used without further purification. PTFE-FEP (polytetrafluoroethylenefluorinated ethylene polypropylene copolymer) NMR tube liners were ordered from Wilmad-LabGlass (USA).

\subsection{Sample preparation}

The dilution series was prepared in a gravimetric manner. Acetonitrile was used as solvent, DMC as heteronuclear standard and monofluorobenzene as analyte from $20 \mathrm{ppm}$ to $200000 \mathrm{ppm}$ (wt). For the quantification, three different samples were prepared: an LP30 electrolyte in PTFE NMR tube liners, an LP30 electrolyte with $1000 \pm 10$ volumetric ppm (vppm) $\mathrm{H}_{2} \mathrm{O}$ in PTFE NMR tube liners and an LP30 electrolyte in NMR glass tubes. Each sample contained $500 \mu \mathrm{L}$ of electrolyte. The NMR tube liners were cut to a length of $12.5 \mathrm{~cm}$ to fit inside the NMR glass tubes and sealed with a PTFE plug. The glass tubes were flame-sealed to achieve gastightness. Due to the distance between the electrolyte sample and the part of the tube that was sealed, the flame-sealing does not heat up the sample. The samples were stored at $60{ }^{\circ} \mathrm{C}$.

\subsection{Measurements}

Each sample was measured three times on each date. The NMR measurements were performed employing an Avance III HD spectrometer (Bruker, USA) at $400 \mathrm{MHz}\left({ }^{1} \mathrm{H}\right)$ and a broadband probe (PA BBO $400 \mathrm{MHz}$, Bruker). The ${ }^{1} \mathrm{H}$ and ${ }^{13} \mathrm{C}$ NMR signals were referenced to the signals of EC at $4.63 \mathrm{ppm}\left({ }^{1} \mathrm{H}\right)$ and $67.1 \mathrm{ppm}\left({ }^{13} \mathrm{C}\right)$, while the ${ }^{19} \mathrm{~F}$ and ${ }^{31} \mathrm{P}$ signals were referenced with respect to the signals of $\mathrm{PF}_{6}{ }^{-}$at $-72.7 \mathrm{ppm}\left({ }^{19} \mathrm{~F}\right)$ and $-146.1 \mathrm{ppm}\left({ }^{31} \mathrm{P}\right)$, respectively. Note that $\operatorname{SiMe}_{4}\left({ }^{1} \mathrm{H}\right.$ and $\left.{ }^{13} \mathrm{C}\right), \mathrm{CCl}_{3} \mathrm{~F}\left({ }^{19} \mathrm{~F}\right)$ and $\mathrm{H}_{3} \mathrm{PO}_{4}$ $\left({ }^{31} \mathrm{P}\right)$ were used as primary standards. The quantification measurements were carried out at $-15{ }^{\circ} \mathrm{C}$. A parameter optimization measurement for the relaxation delay (d1) was used to figure out the required time for full spin relaxation, while a comparison of ${ }^{13} \mathrm{C}$ NMR spectra recorded with and without proton decoupling of pristine and aged electrolyte showed that ongoing degradation of the electrolyte did not influence the NMR signal enhancement of the peak attributed to EC due to broadband decoupling. The acquisition parameters are listed in Table S1 (ESI $\dagger$ ).

\subsection{Data processing}

The NMR spectrometer was controlled by TopSpin ${ }^{\mathrm{TM}} 3.2$ (Bruker, USA). The NMR data processing was done by the same software and also by MestReNova 10.0 (Mestrelab research, Spain). Plotting of graphs and curve fitting was done using OriginPro 2015 (9.2) (OriginLab, USA).

\section{Results and discussion}

\subsection{Quantification}

In the following chapters no distinction between protonated and deprotonated acidic phosphates is made. Concerning the

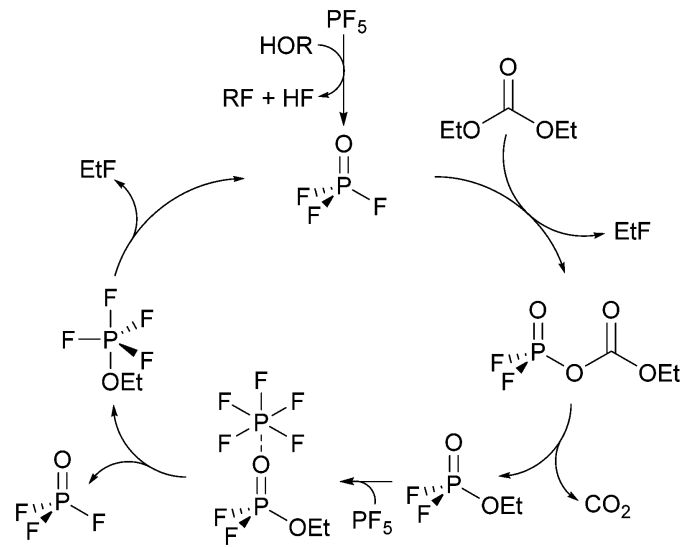

Fig. 1 Autocatalytic reaction mechanism for the degradation of LiPF $_{6}$ in carbonate solvents. ${ }^{11,14}$

degradation of electrolytes at least a cyclic ${ }^{11,14}$ and a linear ${ }^{22,26,29}$ reaction scheme was proposed.

The cyclic reaction scheme (Fig. 1) emphasizes the formation of difluorinated organophosphates and the crucial role of $\mathrm{OPF}_{3}$. Most notably, actual electrolyte degradation according to this reaction scheme should result in both significant accumulation of $\mathrm{OPF}_{3}$ and subsequently increasing degradation rates. In contrast, the linear reaction mechanism considers solely reaction of $\mathrm{PF}_{5}$ with water as the source of $\mathrm{OPF}_{3}$, followed by substitution reactions indicating that electrolyte degradation does not pile up $\mathrm{OPF}_{3}$ so that the degradation rate should not increase. In order to corroborate a cyclic reaction scheme, a quantification of $\mathrm{OPF}_{2} \mathrm{OEt}$, a degradation product of $\mathrm{LiPF}_{6}$ and diethyl carbonate, was reported though the data interpretation in part remained ambiguous. ${ }^{11,14}$ In an attempt to more thoroughly elucidate the possible routes of electrolyte aging, while considering that likely occurring degradation products of $\mathrm{PF}_{6}{ }^{-}$contain NMR active nuclei, quantitative ${ }^{19} \mathrm{~F}$ NMR spectroscopy appears as suitable method. Nevertheless, reliable quantification of reaction species present in a considered sample via solution NMR spectroscopy often requires the addition of an internal standard. ${ }^{30}$ This standard should be chemically inert (neither changing over time nor taking part in degradation reactions) while the corresponding NMR signal should be unaffected by signals of occurring degradation products. Therefore, monofluorobenzene, hexafluorobenzene, monofluoronaphthalene and trichlorofluoromethane were evaluated as potential standards, applying flame-sealed standard NMR glass tubes or polytetrafluoroethylene (PTFE) NMR tube liners (to prevent a potential reaction of HF with glass). However, none of the considered compounds met all requirements for an internal standard in both types of sample containers (chapter S3.1, ESI $\dagger$ ). Therefore, an NMR method was implemented that does not rely on the addition of a standard compound but rather utilizes a species present in the sample. Indeed, many compounds with methyl groups were found in aged electrolytes, likely originating from DMC, while only two degradation products containing ethylene groups were found. The initial amount of EC may thus be represented by the sum of integrated 
signal areas of EC and its associated decomposition products such as dimethyl-2,5-dioxahexane di-carboxylate (DMDOHC) and 2-methoxyethyl methyl carbonate (MEMC) in the corresponding ${ }^{1} \mathrm{H}$ or ${ }^{13} \mathrm{C}\left\{{ }^{1} \mathrm{H}\right\}$ solution NMR spectra $\left(I_{0}(\mathrm{EC})\right)$. The latter compounds are solely identified in the case of considerably aged electrolytes.

Based on quantitative ${ }^{1} \mathrm{H}$ or $\left.{ }^{13} \mathrm{C}_{\{1}{ }^{1} \mathrm{H}\right\}$ and ${ }^{19} \mathrm{~F}$ NMR data the actual $\mathrm{PF}_{6}{ }^{-}$concentration $c\left(\mathrm{PF}_{6}{ }^{-}\right)$during electrolyte degradation can be obtained from the expression

$$
c\left(\mathrm{PF}_{6}^{-}\right)=c_{0}\left(\mathrm{PF}_{6}^{-}\right) \cdot \frac{I\left(\mathrm{PF}_{6}\right) \cdot I_{0}(\mathrm{EC})}{I_{0}\left(\mathrm{PF}_{6}^{-}\right) \cdot I(\mathrm{EC})}
$$

where $c_{0}$ is the initial concentration, $I$ is the actual integrated signal area and $I_{0}$ the initial integrated signal area of the considered species. Note that this NMR based quantification approach requires steady acquisition parameters including NMR hardware aspects such as probe tuning and temperature control. Though in principle both the ${ }^{1} \mathrm{H}$ and ${ }^{13} \mathrm{C}\left\{{ }^{1} \mathrm{H}\right\}$ NMR signal of EC may be used as internal reference, the significantly narrower ${ }^{13} \mathrm{C}\left\{{ }^{1} \mathrm{H}\right\}$ signal is preferred. All quantitative data presented in this work is based on ${ }^{19} \mathrm{~F}$ NMR signal areas of analytes and ${ }^{13} \mathrm{C}\left\{{ }^{1} \mathrm{H}\right\}$ NMR signal areas of heteronuclear standards. The suitability of NMR to reliably quantify the species of interest is documented by a dilution series of monofluorobenzene in acetonitrile with a constant concentration of DMC (Fig. 2). Indeed, the normalized integrated peak area ratios reflecting increasing contents of monofluorobenzene showed a good linearity and relative standard deviations (RSD) below $1 \%$ where the limit of quantification (LOQ) was found at $200 \mu \mathrm{mol} \mathrm{L}^{-1}$ corresponding to a fluorine content of $3.8 \mathrm{ppm}$. Subsequently, insight into the decomposition of $\mathrm{PF}_{6}{ }^{-}$in the presence of water was obtained from unambiguously monitoring the concentration of $\mathrm{HF}, \mathrm{OPF}_{2} \mathrm{OH}, \mathrm{OPF}_{2} \mathrm{OMe}$ and monofluorinated phosphates, respectively. The results are utilized to refine or augment previously reported $\mathrm{PF}_{6}{ }^{-}$degradation schemes (Fig. 3), ${ }^{11,16,25,26}$

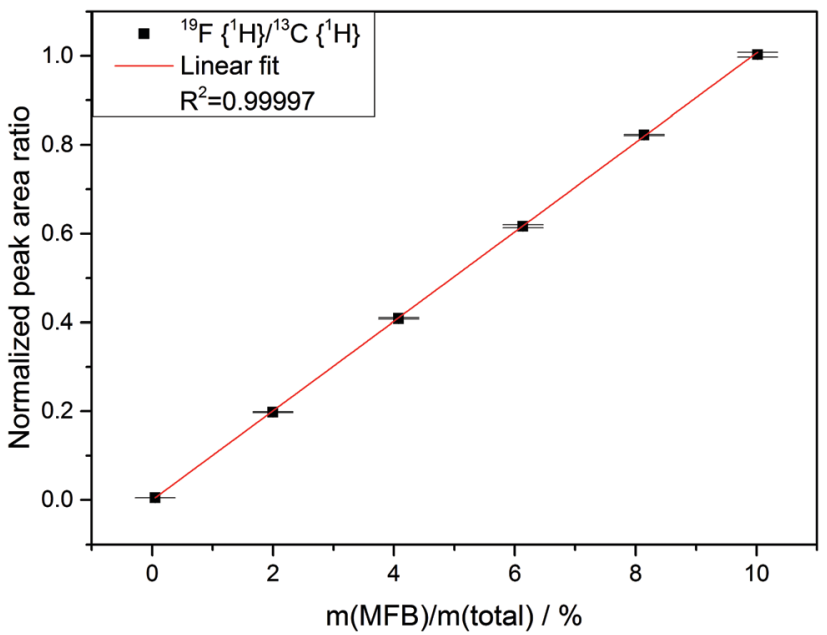

Fig. 2 Dilution series of monofluorobenzene (MFB) in acetonitrile with a constant concentration of DMC. Normalized peak area ratio obtained from ${ }^{19} \mathrm{~F}\left\{{ }^{1} \mathrm{H}\right\}$ and ${ }^{13} \mathrm{C}\left\{{ }^{1} \mathrm{H}\right\}$ NMR measurements. The lowest of the plotted data points is $0.05 \%$ (wt) MFB.

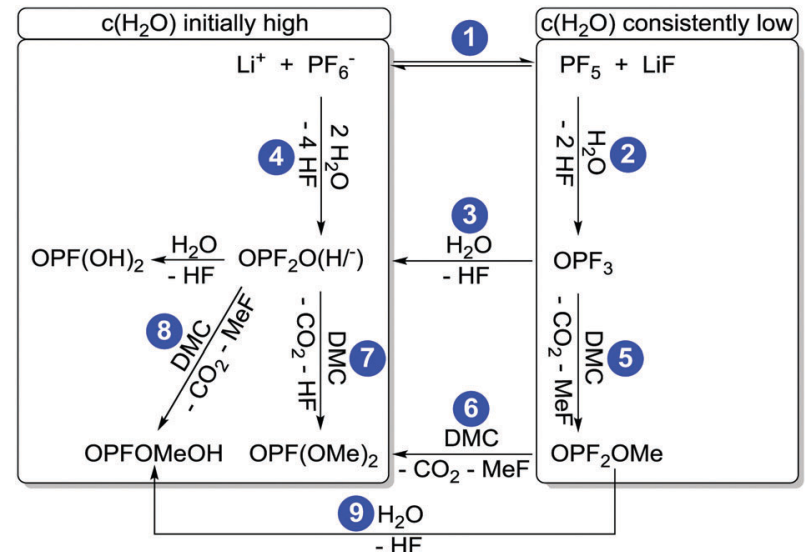

Fig. 3 Proposed reaction scheme of $\mathrm{PF}_{6}{ }^{-}$degradation. Frames highlight predominant "linear" reaction routs in the case of initially added high amounts of water ( $\mathrm{LP} 30+\mathrm{H}_{2} \mathrm{O}$, PTFE) and in the presence of rather low concentrations of water (LP30, glass).

while expanding molecular understanding of the underlying reaction steps.

Due to hydrolysis of $\mathrm{PF}_{5}$ and $\mathrm{PF}_{6}{ }^{-}$(reaction routes 2 and 4) $\mathrm{HF}$ will be released at the onset of degradation, therefore the concentration curves of $\mathrm{HF}$ in case of three different types of samples were observed (Fig. 4) for a period of 56 days. As anticipated all the samples with an addition of $1000 \pm 10 \mathrm{vppm}$ of water exhibited a rather strong increase of the HF concentration to $110 \pm 5 \mathrm{mmol} \mathrm{L}^{-1}$ after one day, which is twice the initial water concentration $\left(55.6 \pm 0.6 \mathrm{mmol} \mathrm{L}^{-1}\right)$ and in agreement with reaction route 4 (and possibly 1,2 and 3). The subsequently identified decrease of the HF concentration suggests that HF in part even escaped from the PTFE NMR tube, though no significant impact on the actual mechanism of electrolyte degradation is expected. In contrast, the samples without water addition revealed much lower HF concentrations. For "LP30, PTFE" the HF concentration rather slowly

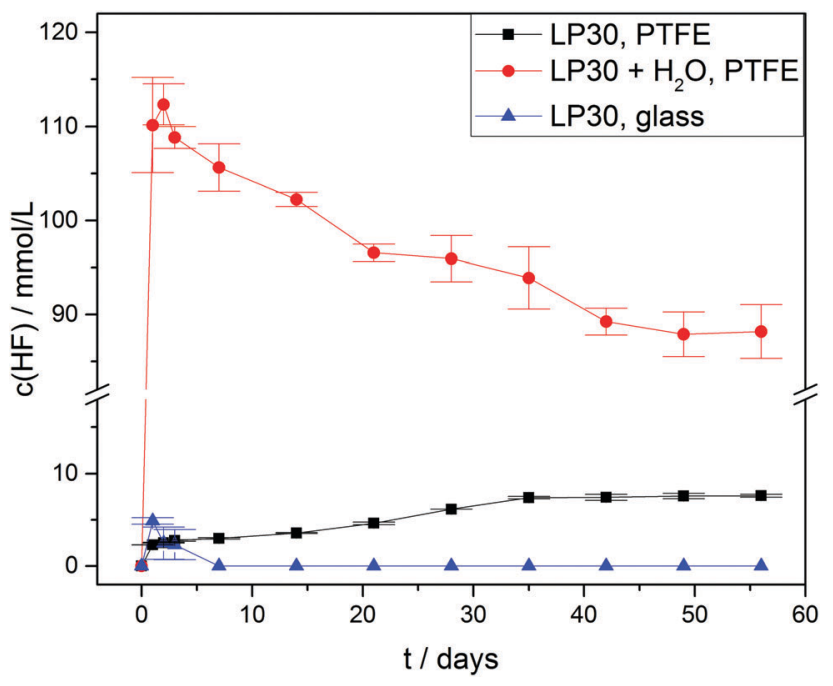

Fig. $4 \mathrm{HF}$ concentration curves of LP30 stored at $60{ }^{\circ} \mathrm{C}$. Lines serve as guide to the eye. 


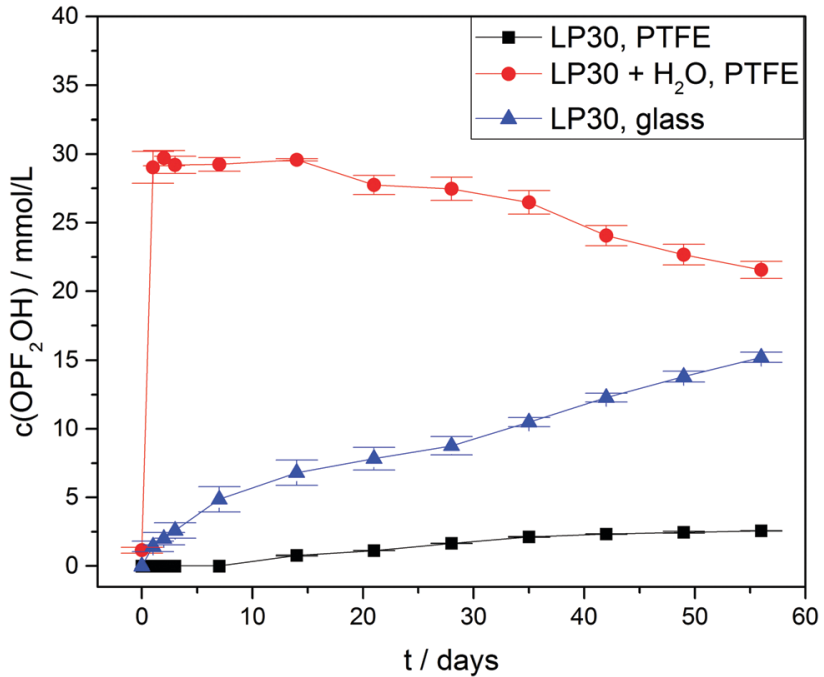

Fig. $5 \mathrm{OPF}_{2} \mathrm{OH}$ concentration curves of LP30 stored at $60{ }^{\circ} \mathrm{C}$. Lines serve as guide to the eye.

increased to $7.6 \pm 0.2 \mathrm{mmol} \mathrm{L}^{-1}$ after eight weeks while negligibly small amounts of $\mathrm{HF}$ were detectable in case of "LP30, glass" during the first days. In the latter sample, HF disappeared after one week due to the reaction with the NMR glass tube yielding $\mathrm{BF}_{4}{ }^{-}$and $\mathrm{H}_{2} \mathrm{O}$. Notably, the concentration of $\mathrm{OPF}_{2} \mathrm{OH}$ rapidly increased in the samples with water addition, thus during one day reaching $29 \pm 1.2 \mathrm{mmol} \mathrm{L}^{-1}$ (Fig. 5) in agreement with reaction route 4 . The subsequent decrease of $\mathrm{OPF}_{2} \mathrm{OH}$ concentration to $21.6 \pm 0.6 \mathrm{mmol} \mathrm{L}^{-1}$ during the observation period of 56 days is attributed to substitution reactions according to reaction routes 7 and 8, yielding monofluorinated phosphates. Likewise, for the samples stored in glass tubes (LP30, glass) the concentration of $\mathrm{OPF}_{2} \mathrm{OH}$ increased continuously to a value of $15.2 \pm 0.4 \mathrm{mmol} \mathrm{L}^{-1}$ at the end of the measurement period, reflecting the reaction of

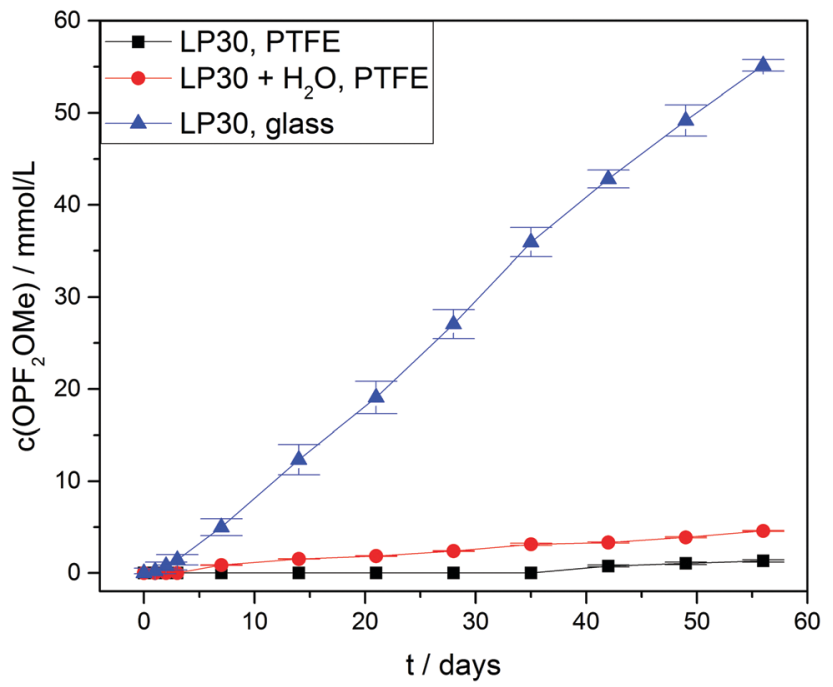

Fig. $6 \mathrm{OPF}_{2} \mathrm{OMe}$ concentration curves of LP30 stored at $60{ }^{\circ} \mathrm{C}$. Lines serve as guide to the eye.

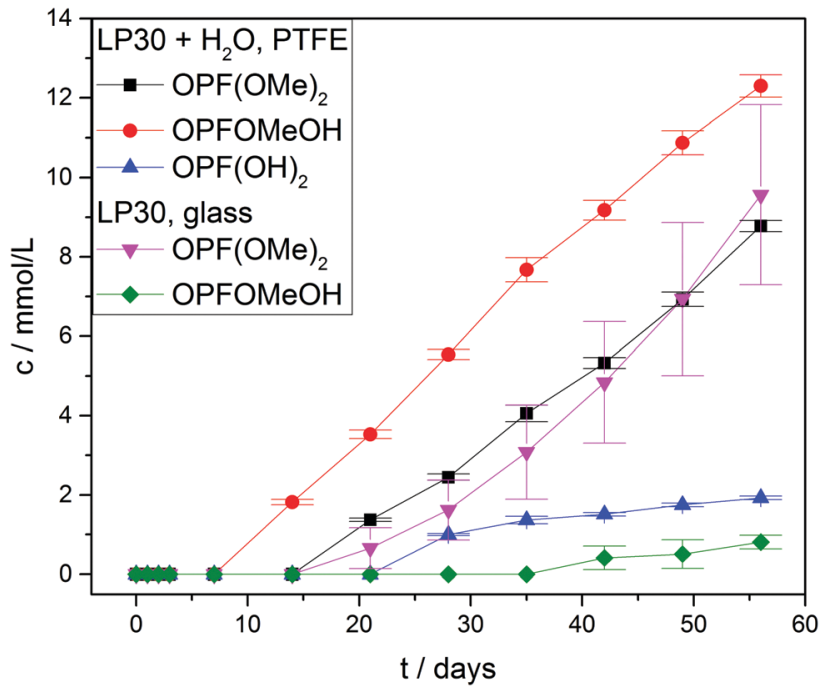

Fig. 7 Concentration curves of monofluorinated phosphates. Concentrations in the PTFE tube samples without water addition are below the LOQ. Lines serve as guide to the eye.

HF with glass and accompanied release of water that corroborate an ongoing formation of $\mathrm{OPF}_{2} \mathrm{OH}$. Without water addition the formation of $\mathrm{OPF}_{2} \mathrm{OH}$ in the PTFE tube samples is almost negligible, reaching merely $2.56 \pm 0.01 \mathrm{mmol} \mathrm{L}^{-1}$ after eight weeks.

For the difluorinated phosphates $\mathrm{OPF}_{2} \mathrm{OH}$ and $\mathrm{OPF}_{2} \mathrm{OMe}$ remarkably different rates of formation were identified. While the formation of $\mathrm{OPF}_{2} \mathrm{OH}$ was very pronounced in those samples where additional water was added $\left(21.6 \pm 0.6 \mathrm{mmol} \mathrm{L}^{-1}\right)$, the concentration of $\mathrm{OPF}_{2} \mathrm{OMe}$ solely reached $4.57 \pm 0.05 \mathrm{mmol} \mathrm{L}^{-1}$ after eight weeks of aging (Fig. 6). In contrast, the samples stored in glass NMR tubes exhibited a maximum $\mathrm{OPF}_{2} \mathrm{OMe}$ concentration of $55.2 \pm 0.6 \mathrm{mmol} \mathrm{L}^{-1}$ while for $\mathrm{OPF}_{2} \mathrm{OH}$ a maximum concentration of $15.2 \pm 0.4 \mathrm{mmol} \mathrm{L}^{-1}$ was determined. In principle, this observation may be rationalized based on the proposed reaction scheme (Fig. 3) provided that the reaction of $\mathrm{PF}_{5}$ with water is favored over the reaction of $\mathrm{PF}_{6}{ }^{-}$with water. However, the presented equilibrium (reaction 1) is far on the left side (since the fresh electrolyte predominantly contains $\mathrm{PF}_{6}{ }^{-}$) thereby promoting a reaction of water with $\mathrm{PF}_{6}{ }^{-}$so that it appears reasonable to assume that initially added water primarily reacts with $\mathrm{PF}_{6}{ }^{-}$until it is almost consumed (reaction path 4). In contrast, in the presence of rather small amounts of water the equilibrium reaction 1 could deliver sufficient amounts of $\mathrm{PF}_{5}$ that further react with traces of water, in this way following the reaction paths 2 and 5 . This scenario is feasible for the electrolytes stored in glass tubes where a minor amount of water is permanently present, hence suggesting that preferred reaction paths for electrolyte degradation are influenced by the overall amount of water present in the sample or eventually added and whether or not the critical amount of water is provided in one batch at first or continuously formed over time. It has to be noted that no NMR signals assigned to $\mathrm{PF}_{5}$ are found, which is in agreement with its character as a highly reactive intermediate. 
Fig. 7 shows the measured concentrations of monofluorinated phosphates. These degradation products were only found in the "LP30 $+\mathrm{H}_{2} \mathrm{O}$, PTFE" and "LP30, glass" samples. The concentrations in the samples with water addition show an almost constant slope, whereas the slope of $\mathrm{OPF}(\mathrm{OMe})_{2}$ increases over time in the glass tubes. The reason for this is most likely the formation of the monofluorinated phosphates by a reaction of difluorinated phosphates with DMC (Fig. 3 reaction routes 6,7 and 8). Reaction routes 6 and 8 are previously proposed based on qualitative data about electrolyte degradation products. ${ }^{22,26,29}$ The results of this work confirm these proposals. Furthermore, it has to be noted that only quantitative studies are able to reveal reaction route 7 by comparing the product's formation rate with the reactants concentration. The formation of $\mathrm{OPFOMeOH}$ in the glass tube samples most likely proceeds according to reaction routes 8 and 9.

The autocatalytic reaction mechanism (Fig. 1) for the degradation of $\mathrm{LiPF}_{6}$ in carbonate based solvents indicates the $\mathrm{OPF}_{3}$ species as main driving force of the overall reaction where consumption of one $\mathrm{OPF}_{3}$ molecule eventually results in the release of two further $\mathrm{OPF}_{3}$ molecules, thereby accelerating the electrolyte degradation rate, accompanied by subsequent accumulation of $\mathrm{OPF}_{3}$. The accumulation of $\mathrm{OPF}_{3}$, however, was not observed within this work. Rather, the NMR based quantification of the occurring reaction species clearly

Table 1 Identified compounds found in thermally aged LP30 electrolyte, NMR signal specifications and concentrations $c$ after eight weeks of aging at $60{ }^{\circ} \mathrm{C}$

\begin{tabular}{|c|c|c|c|c|c|}
\hline Compound & $\begin{array}{l}\delta\left({ }^{1} \mathrm{H}\right) / \mathrm{ppm} \\
\left(J\left({ }^{1} \mathrm{H}^{-}{ }^{1} \mathrm{H}\right), J\left({ }^{1} \mathrm{H}^{31}{ }^{31} \mathrm{P}\right)\right)\end{array}$ & $\begin{array}{l}\delta\left({ }^{13} \mathrm{C}\left\{{ }^{1} \mathrm{H}\right\}\right) / \\
\operatorname{ppm}\end{array}$ & $\begin{array}{l}\delta\left({ }^{19} \mathrm{~F}\right) / \mathrm{ppm} \\
\left(J\left({ }^{19} \mathrm{~F}-{ }^{31} \mathrm{P}\right)\right)\end{array}$ & $\delta\left({ }^{31} \mathrm{P}\right) / \mathrm{ppm}\left(J\left({ }^{19} \mathrm{~F}-{ }^{31} \mathrm{P}\right), J\left({ }^{1} \mathrm{H}-{ }^{31} \mathrm{P}\right)\right)$ & $\begin{array}{l}c(t=56 \text { days }) / \\
\text { mmol }^{-1} \mathrm{~L}^{-1} \\
\mathrm{LP} 30 ; \\
\mathrm{LP} 30+\mathrm{H}_{2} \mathrm{O} ; \\
\mathrm{LP} 30 \text { glass }\end{array}$ \\
\hline EC & $4.63(\mathrm{~s})$ & $\begin{array}{l}67.1 \\
158.7\end{array}$ & - & - & - \\
\hline DMC & $3.81(\mathrm{~s})$ & $\begin{array}{l}56.0 \\
158.2\end{array}$ & - & - & - \\
\hline $\mathrm{PF}_{6}^{-}$ & - & - & $-72.70(\mathrm{~d}, 708 \mathrm{~Hz})$ & -146.1 (sept, $708 \mathrm{~Hz})$ & $\begin{array}{l}996 \pm 16 \\
956 \pm 20 \\
895 \pm 8\end{array}$ \\
\hline $\mathrm{CH}_{3} \mathrm{OCH}_{3}$ & $3.37(\mathrm{~s})$ & 61.1 & - & - & - \\
\hline $\mathrm{CH}_{2} \mathrm{CH}_{2}$ & $5.80(\mathrm{~s})$ & - & - & - & - \\
\hline $\mathrm{CO}_{2}$ & - & 126.3 & - & - & - \\
\hline DMDOHC & $4.41(\mathrm{~s})$ & $\begin{array}{l}67.2 \\
157.3\end{array}$ & - & - & - \\
\hline MEMC & $\begin{array}{l}3.39(\mathrm{~s}) \\
3.67(\mathrm{t}+\mathrm{d}, 1.9,9.1 \mathrm{~Hz}) \\
4.32(\mathrm{t}+\mathrm{d}, 1.9,9.1 \mathrm{~Hz})\end{array}$ & $\begin{array}{l}59.368 .4 \\
71.5 \\
157.7\end{array}$ & - & - & - \\
\hline $\mathrm{OPF}_{3}$ & - & - & $-88.09(\mathrm{~d}, 1066 \mathrm{~Hz})$ & $-36.3(\mathrm{q}, 1066 \mathrm{~Hz})$ & $\begin{array}{l}<\text { LOD; } \\
<\text { LOD; } \\
0.22 \pm 0.01\end{array}$ \\
\hline $\mathrm{OPF}_{2}(\mathrm{OH})$ & - & - & $-83.35(\mathrm{~d}, 930-960 \mathrm{~Hz})$ & $-21.6(t, 930-960 \mathrm{~Hz})$ & $\begin{array}{l}2.56 \pm 0.01 \\
21.6 \pm 0.6 \\
15.2 \pm 0.4\end{array}$ \\
\hline $\mathrm{OPF}_{2}(\mathrm{OMe})$ & $4.22(\mathrm{~d}, 12.0 \mathrm{~Hz})$ & - & $-86.59(\mathrm{~d}, 1008 \mathrm{~Hz})$ & $-21.1(\mathrm{t} ; \mathrm{q}, 1008 \mathrm{~Hz}, 12.2 \mathrm{~Hz})$ & $\begin{array}{l}1.3 \pm 0.1 \\
4.57 \pm 0.05 \\
55.2 \pm 0.6\end{array}$ \\
\hline $\mathrm{OPF}_{2}\left(\mathrm{OCH}_{2} \mathrm{CH}_{2} \mathrm{OMe}\right)^{a}$ & $\begin{array}{l}4.51(\mathrm{~m}) \\
4.77(\mathrm{~m})\end{array}$ & - & $-84.40(\mathrm{~d}, 1007 \mathrm{~Hz})$ & $\begin{array}{l}-21.9(\mathrm{t} ; \mathrm{t} ; \mathrm{t}, 1007 \mathrm{~Hz}, 9.4 \mathrm{~Hz}, \\
1.9 \mathrm{~Hz})\end{array}$ & $\begin{array}{l}<\mathrm{LOD} \\
<\mathrm{LOD} \\
1.36 \pm 0.02\end{array}$ \\
\hline $\mathrm{OPF}(\mathrm{OH})_{2}$ & - & - & $-75.76(d, 926 \mathrm{~Hz})$ & $-10.6(\mathrm{~d}, 926 \mathrm{~Hz})$ & $\begin{array}{l}<\mathrm{LOD} \\
1.93 \pm 0.05 \\
<\mathrm{LOD}\end{array}$ \\
\hline $\mathrm{OPF}(\mathrm{OMe})(\mathrm{OH})$ & $3.98(\mathrm{~d}, 11.7 \mathrm{~Hz})$ & - & $-82.18(\mathrm{~d}, 943 \mathrm{~Hz})$ & $-10.2(\mathrm{~d} ; \mathrm{q}, 943 \mathrm{~Hz}, 11.7 \mathrm{~Hz})$ & $\begin{array}{l}<\mathrm{LOD} \\
12.3 \pm 0.3 \\
0.8 \pm 0.2\end{array}$ \\
\hline $\mathrm{OPF}(\mathrm{OMe})_{2}$ & $4.04(\mathrm{~d}, 11.6 \mathrm{~Hz})$ & - & $-86.73(\mathrm{~d}, 962 \mathrm{~Hz})$ & -9.5 (d; sept, $962 \mathrm{~Hz}, 11.6 \mathrm{~Hz})$ & $\begin{array}{l}<\mathrm{LOD} \\
8.8 \pm 0.1 \\
10 \pm 2\end{array}$ \\
\hline $\mathrm{OPF}_{2}(\mathrm{OH})-\mathrm{BF}_{3}$ & - & - & $\begin{array}{l}-84.40(\mathrm{~d} ; \mathrm{q}, 960 \mathrm{~Hz}, 2.5 \mathrm{~Hz}) \\
-147.78\left({ }^{10} \mathrm{~B}\right)(\mathrm{d} ; \mathrm{t}, 10 \mathrm{~Hz}, 2.5 \mathrm{~Hz}) \\
-147.84\left({ }^{11} \mathrm{~B}\right)(\mathrm{d} ; \mathrm{t}, 10 \mathrm{~Hz}, 2.5 \mathrm{~Hz})\end{array}$ & $-27.6(\mathrm{t} ; \mathrm{q}, 960 \mathrm{~Hz}, 10 \mathrm{~Hz})$ & $\begin{array}{l}<\text { LOD; } \\
<\text { LOD; } \\
0.77 \pm 0.05\end{array}$ \\
\hline $\mathrm{BF}_{4}^{-}$ & - & - & $\begin{array}{l}-154.22\left({ }^{10} \mathrm{~B}\right) \\
-154.27\left({ }^{11} \mathrm{~B}\right)\end{array}$ & - & $\begin{array}{l}<\mathrm{LOD} \\
1.2 \pm 0.1 \\
11.9 \pm 0.2\end{array}$ \\
\hline HF & $9.14(\mathrm{~d}, 474 \mathrm{~Hz})$ & - & $-188.05(\mathrm{~d}, 474 \mathrm{~Hz})$ & - & $\begin{array}{l}7.6 \pm 0.2 \\
88 \pm 3 \\
<\text { LOD }\end{array}$ \\
\hline
\end{tabular}

${ }^{a}$ The signal of the OMe-group was not found. LOD: limit of detection. 
revealed that the degradation rates of pristine and aged electrolytes are comparable. In addition, the presence of $\mathrm{OPF}_{3}\left({ }^{19} \mathrm{~F}\right.$ NMR signal at $\left.-88.9 \mathrm{ppm}\right)$ could be detected only in the case of samples stored in NMR glass tubes at rather constant amounts. These observations are not in favor of a "cyclic" autocatalytic reaction mechanism but corroborate electrolyte aging according to an augmented linear reaction scheme (Fig. 3). ${ }^{22,26,29}$

Note that the reaction paths 6 and 8 were previously introduced based on qualitative inspection of electrolyte degradation products ${ }^{22,26,29}$ and are supported by this work while the reaction routes 4,7 and 9 were identified from concentration curves and comparison of the concentrations of difluorinated phosphates with the formation rate of monofluorinated phosphates, hence from quantitative data of this work. Since the samples stored in PTFE tubes without the presence of water revealed minor degradation while all the others exhibited significant aging (as established from residual concentrations of $\mathrm{PF}_{6}{ }^{-}$after eight weeks, see Table 1) it appears that chemical instability of the electrolyte with respect to water rather than with respect to elevated temperatures is responsible for the observable degradation over time.

\subsection{Identification}

The identification of degradation products and assignment of their NMR signals are crucial steps prior to quantification. Besides the necessity of knowing the compounds that are to be quantified, it is required that all degradation products of the chosen heteronuclear standard (EC) are found. If EC is not completely stable, its degradation products have to be taken into account for an accurate quantification.

The ESI $\dagger$ contain a detailed description of the identification strategy and the complex measurements which were necessary for the signal assignment. All identified compounds are listed in Table 1. Two compounds, namely dimethyl-2,5dioxahexane dicarboxylate (DMDOHC) and 2-methoxyethyl methyl carbonate (MEMC) are found as degradation products of EC (Fig. S5, ESI $\dagger$ ).

The ${ }^{19} \mathrm{~F}$ NMR spectrum of electrolyte LP30 stored in NMR glass tubes at $60{ }^{\circ} \mathrm{C}$ contains two singlets at approx. $-154 \mathrm{ppm}$ (Fig. 8). The ratio of their integrated signal areas is $1: 4$. According to literature the ${ }^{19} \mathrm{~F}$ NMR signal of $\mathrm{HF}$ is a singlet at the same chemical shift. ${ }^{11,12,20}$ However, the ratio of the integrated signal areas is identical with the isotopic signature of boron $\left(20 \%{ }^{10} \mathrm{~B}, 80 \%{ }^{11} \mathrm{~B}\right)$, suggesting the presence of $\mathrm{BF}_{4}{ }^{-}$ formed by reaction of $\mathrm{HF}$ with the borate glass of the NMR tube. Furthermore, the ${ }^{19} \mathrm{~F}$ NMR signal of $\mathrm{BF}_{4}{ }^{-}$is known to be at the above mentioned chemical shift. ${ }^{31}$ The different masses of the isotopes lead to different mean distances between the fluorine and boron atoms, which influences the chemical shift. ${ }^{32}$ The assignment to $\mathrm{BF}_{4}{ }^{-}$is confirmed by ${ }^{19} \mathrm{~F}$ measurements of an electrolyte sample with additional $\mathrm{LiBF}_{4}$.

The actual HF signal in the ${ }^{19} \mathrm{~F}$ NMR spectrum can be found when PFTE NMR tube liners are used. It is a doublet at -188.05 ppm with a ${ }^{1} J\left({ }^{1} \mathrm{H}^{-19} \mathrm{~F}\right)$ coupling constant of $474 \mathrm{~Hz}$

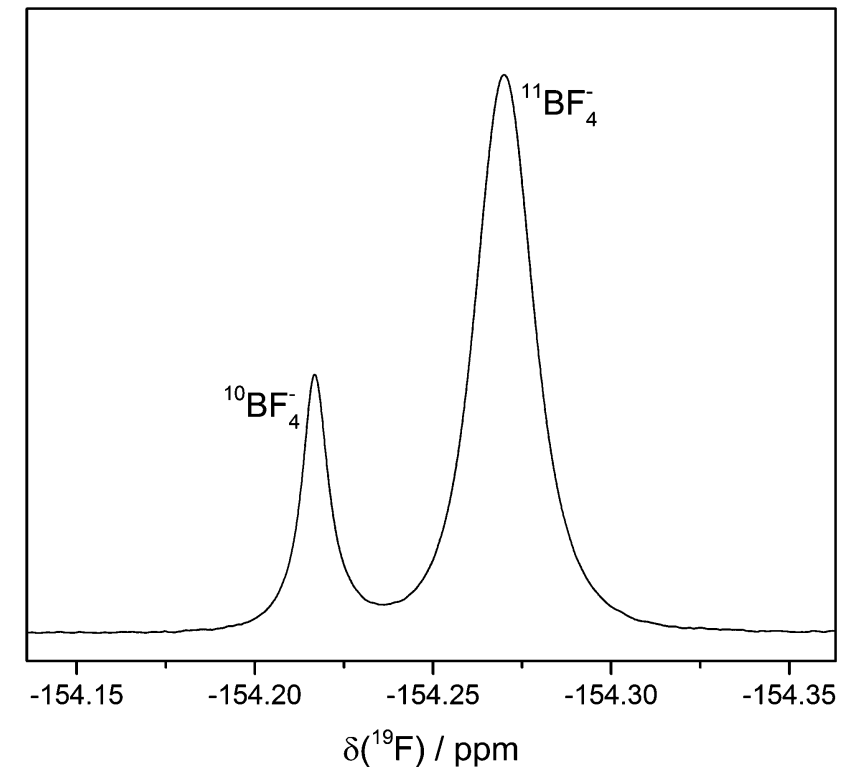

Fig. $8{ }^{19} \mathrm{~F}$ signals of $\mathrm{BF}_{4}{ }^{-}$. LP30 stored in NMR glass tubes at $60{ }^{\circ} \mathrm{C}$. The two different singlets are caused by the two boron isotopes. Line broadening: $0.5 \mathrm{~Hz}$.

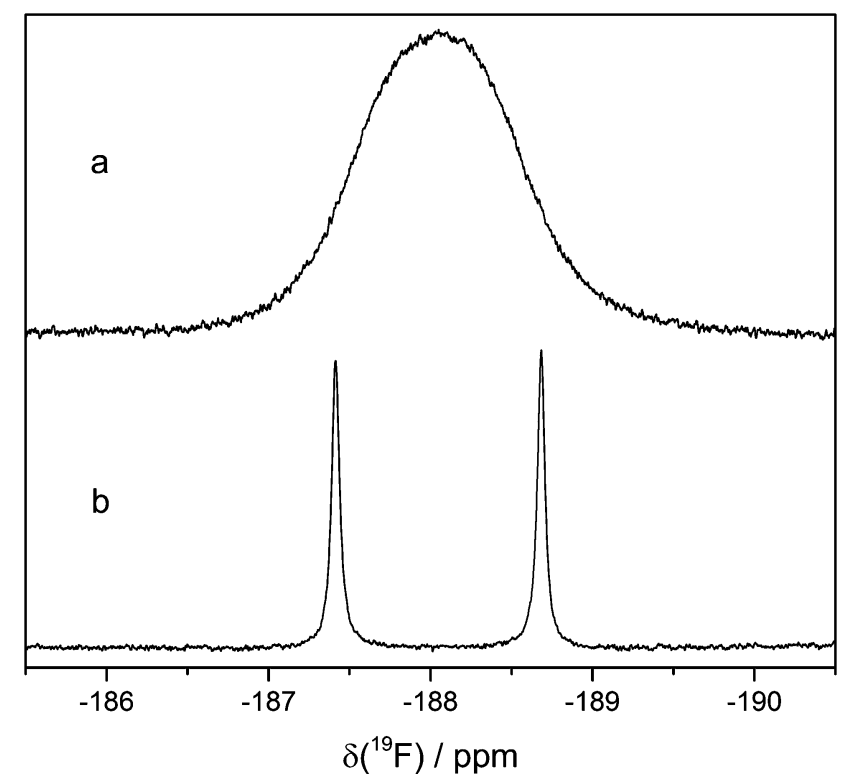

Fig. $9{ }^{19} \mathrm{~F}$ signals of HF. Aged LP30 with (a) and without (b) water addition. Line broadening: $2 \mathrm{~Hz}$.

(Fig. 9). To the best of our knowledge, this is the first time the ${ }^{1} \mathrm{H}^{-19} \mathrm{~F}$ coupling of $\mathrm{HF}$ is observed, most likely because the exchange of protons in the presence of protic compounds usually leads to the observation of a singlet. In this work, the addition of $1000 \mathrm{vppm}$ water leads to broad singlets in the ${ }^{19} \mathrm{~F}$ and ${ }^{1} \mathrm{H}$ spectra at the chemical shifts of HF. Fluoride and $\mathrm{HF}$ can form clusters of the formula $\left[\mathrm{F}(\mathrm{HF})_{n}\right]^{-.33}$. Since the corresponding ${ }^{1} \mathrm{H}$ signal at $9.14 \mathrm{ppm}$ is also a doublet, there is no more than one coupling partner of the ${ }^{1} \mathrm{H}$ hence no clusters are present. 


\section{Conclusions}

A facile NMR method for reliable quantification of species occurring during thermal aging of electrolytes was developed and applied to expand the under-standing of molecular processes thereby affording detailed insight into the underlying reaction mechanisms, which in principle are suitable for enhanced battery safety evaluations. In contrast to previous reports it was successfully demonstrated that electrolyte degradation proceeds at similar rates in pristine and already aged electrolytes upon thermal treatment. In addition, the collected NMR data strongly suggests that water not only reacts with $\mathrm{PF}_{5}$ but also with $\mathrm{PF}_{6}{ }^{-}$, in this way critically determining the actually occurring degradation products. While an excess of water forces hydrolysis of $\mathrm{PF}_{6}{ }^{-}$ hence yielding $\mathrm{OPF}_{2} \mathrm{OH}$, the continuous presence of rather small amounts of water (e.g., due to almost constant release from glass materials) results in predominant formation of $\mathrm{OPF}_{2} \mathrm{OMe}$ whereas negligible electrolyte degradation is observable in the absence of water, in this way highlighting the critical effects of different water concentrations in electrolytes.

\section{Acknowledgements}

The authors would like to thank the Bundesministerium für Bildung und Forschung (Federal Ministry of Education and Research, Germany) for funding the project "Elektrolytlabor 4e".

\section{References}

1 G. G. Amatucci, J. M. Tarascon and L. C. Klein, J. Electrochem. Soc., 1996, 143, 1114-1123.

2 D. Aurbach, M. D. Levi, K. Gamulski, B. Markovsky, G. Salitra, E. Levi, U. Heider, L. Heider and R. Oesten, J. Power Sources, 1999, 81-82, 472-479.

3 A. K. Padhi, K. S. Nanjundaswamy and J. B. Goodenough, J. Electrochem. Soc., 1997, 144, 1188-1194.

4 M. Winter, J. O. Besenhard, M. E. Spahr and P. Novák, Adv. Mater., 1998, 10, 725-763.

5 T. Placke, V. Siozios, R. Schmitz, S. F. Lux, P. Bieker, C. Colle, H. W. Meyer, S. Passerini and M. Winter, J. Power Sources, 2012, 200, 83-91.

6 J. Kasnatscheew, M. Evertz, B. Streipert, R. Wagner, R. Klopsch, B. Vortmann, H. Hahn, S. Nowak, M. Amereller, A. C. Gentschev, P. Lamp and M. Winter, Phys. Chem. Chem. Phys., 2016, 18, 3956-3965.

7 D. Aurbach, A. Zaban, A. Schechter, Y. Ein-Eli, E. Zinigrad and B. Markovsky, J. Electrochem. Soc., 1995, 142, 2873-2882.

8 U. Heider, R. Oesten and M. Jungnitz, J. Power Sources, 1999, 81-82, 119-122.

9 S. E. Sloop, J. K. Pugh, S. Wang, J. B. Kerr and K. Kinoshita, Electrochem. Solid-State Lett., 2001, 4, A42-A44.

10 B. Ravdel, K. M. Abraham, R. Gitzendanner, J. DiCarlo, B. Lucht and C. Campion, J. Power Sources, 2003, 119-121, 805-810.
11 C. L. Campion, W. Li and B. L. Lucht, J. Electrochem. Soc., 2005, 152, A2327-A2334.

12 A. V. Plakhotnyk, L. Ernst and R. Schmutzler, J. Fluorine Chem., 2005, 126, 27-31.

13 T. Kawamura, S. Okada and J.-i. Yamaki, J. Power Sources, 2006, 156, 547-554.

14 C. L. Campion, W. Li, W. B. Euler, B. L. Lucht, B. Ravdel, J. F. DiCarlo, R. Gitzendanner and K. M. Abraham, Electrochem. Solid-State Lett., 2004, 7, A194-A197.

15 G. Gachot, S. Grugeon, M. Armand, S. Pilard, P. Guenot, J.-M. Tarascon and S. Laruelle, J. Power Sources, 2008, 178, 409-421.

16 W. Weber, V. Kraft, M. Grützke, R. Wagner, M. Winter and S. Nowak, J. Chromatogr. A, 2015, 1394, 128-136.

17 C. Schultz, V. Kraft, M. Pyschik, S. Weber, F. Schappacher, M. Winter and S. Nowak, J. Electrochem. Soc., 2015, 162, A629-A634.

18 G. g. Gachot, P. Ribière, D. Mathiron, S. Grugeon, M. Armand, J.-B. Leriche, S. Pilard and S. p. Laruelle, Anal. Chem., 2010, 83, 478-485.

19 M. Grützke, V. Kraft, W. Weber, C. Wendt, A. Friesen, S. Klamor, M. Winter and S. Nowak, J. Supercrit. Fluids, 2014, 94, 216-222.

20 P. Handel, G. Fauler, K. Kapper, M. Schmuck, C. Stangl, R. Fischer, F. Uhlig and S. Koller, J. Power Sources, 2014, 267, 255-259.

21 L. Terborg, S. Weber, S. Passerini, M. Winter, U. Karst and S. Nowak, J. Power Sources, 2014, 245, 836-840.

22 M. Grutzke, V. Kraft, B. Hoffmann, S. Klamor, J. Diekmann, A. Kwade, M. Winter and S. Nowak, J. Power Sources, 2015, 273, 83-88.

23 L. Gireaud, S. Grugeon, S. Pilard, P. Guenot, J.-M. Tarascon and S. Laruelle, Anal. Chem., 2006, 78, 3688-3698.

24 L. Terborg, S. Nowak, S. Passerini, M. Winter, U. Karst, P. R. Haddad and P. N. Nesterenko, Anal. Chim. Acta, 2012, 714, 121-126.

25 L. Terborg, S. Weber, F. Blaske, S. Passerini, M. Winter, U. Karst and S. Nowak, J. Power Sources, 2013, 242, 832-837.

26 V. Kraft, M. Grützke, W. Weber, J. Menzel, S. WiemersMeyer, M. Winter and S. Nowak, J. Chromatogr. A, 2015, 1409, 201-209.

27 V. Kraft, M. Grutzke, W. Weber, M. Winter and S. Nowak, J. Chromatogr. A, 2014, 1354, 92-100.

28 S. Wilken, P. Johansson and P. Jacobsson, Solid State Ionics, 2012, 225, 608-610.

29 B. Vortmann, S. Nowak and C. Engelhard, Anal. Chem., 2013, 85, 3433-3438.

30 S. K. Bharti and R. Roy, TrAC, Trends Anal. Chem., 2012, 35, $5-26$.

31 V. N. Plakhotnyk, L. Ernst, P. Sakhaii, N. F. Tovmash and R. Schmutzler, J. Fluorine Chem., 1999, 98, 133-135.

32 H. S. Gutowsky, J. Chem. Phys., 1959, 31, 1683-1684.

33 I. G. Shenderovich, S. N. Smirnov, G. S. Denisov, V. A. Gindin, N. S. Golubev, A. Dunger, R. Reibke, S. Kirpekar, O. L. Malkina and H.-H. Limbach, Ber. Bunsen-Ges., 1998, 102, 422-428. 